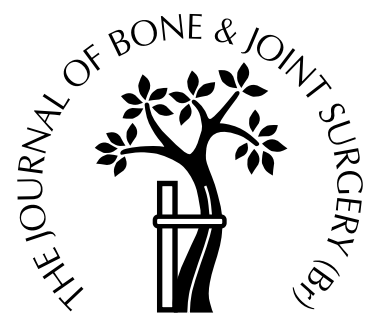

\title{
Editorial
}

\section{EDITORIAL SUCCESSION AT THE JBJS}

Frank Horan has been Editor of the JBJS for five years, but his apprenticeship and association with the Journal extends over a much longer period. In his own words, he has throughout his career considered himself to be a "Journal Man". He has always shown a splendid clarity of view; that the Journal should remain pre-eminent in orthopaedic research. It should contain the best, carefully peer-reviewed articles and be presented succinctly with clarity and brevity. Frank has travelled widely to explain and support his philosophy and to teach how papers should be written and assessed.

Five to six times annually, the Editorial Board meets to consider whether those submitted papers which cause a divergence of opinion among reviewers should be published. Frank leads these discussions with a dry, caustic wit, which has always served to enlighten and enliven debate. It remains an honour to be selected as a reviewer for the JBJS and Frank's enthusiasm for the job has ensured that willing surgeons abound. Although he is stepping down as Editor, I am delighted that he will continue to serve as Emeritus Editor.

While regretting Frank's departure, it is a great pleasure to welcome his successor, Mr James Scott. After training at Oxford and the Middlesex Hospital in London, James completed his Higher Surgical Training in Oswestry and London. He was Consultant Orthopaedic Surgeon at The Chelsea and Westminster Hospital and spent three years as Director of Surgery. He has been associate editor of International Orthopaedics and deputy editor of the JBJS. It is clear that he will develop his own style and that the Journal will change subtly. He shares Frank's vision, however, of producing a Journal of outstanding quality with relevance and importance to orthopaedic surgeons worldwide.

Michael K. D. Benson (Chairman) 